\title{
Consoantes palatais como geminadas fonológicas no Português Brasileiro*
}

W. Leo Wetzels

Universidade Livre de Amsterdam Instituto de Lingüística Gerativa da Holanda (HIL)

\section{Abstract}

In this paper we observe that $/ \tilde{\mathbf{n}} /$ behaves in many respects differently from $/ \mathrm{m}, \mathrm{n} /$. Whereas $/ \mathrm{m}, \mathrm{n} /$ can be preceded by a branching rhyme, $/ \tilde{\mathrm{n}} /$ cannot. When $/ \tilde{\mathrm{n}} /$ occurs between the last two vowels of a word that is at least trisyllabic, stress can never 'skip' the prefinal syllable. On the other hand, when $/ \mathrm{m}, \mathrm{n} /$ occupy the onset of a word-final syllable, proparoxitonic stress does occur (ébano, ágamo). Also, $/ \tilde{\mathrm{n}} /$ does not occur word-initially, in which position $/ \mathrm{m}, \mathrm{n} /$ are frequently found. Furthermore, syllable structure typically splits a $/ V\{i, u\} /$ sequence into two syllables before $[K]$ and [ñ], but not before $/ \mathrm{m}, \mathrm{n} /$. Finally, before the palatal nasal, allophonic nasalisation of a preceding unstressed vowel is obligatory, whereas allophonic nasal spreading does not affect unstressed vowels before $/ \mathrm{m}, \mathrm{n} /$. We will show that all these facts are readily explained by the hypothesis that the palatal sonorants of BP are geminate consonants at the lexical level. 


\section{INTRODUÇÃO}

$1 \begin{aligned} & \text { s soantes palatais } / \tilde{n}, K / \text { do Português Brasileiro (PB) se } \\ & \text { comportam, sob muitos aspectos, diferentemente das } \\ & \text { sóantes não palatais. Em se tratando da nasalização da vogal }\end{aligned}$ precedente, a nasal-palatal se comporta como se fosse uma consoante na coda, embora ela ocorra exclusivamente em posição intervocálica. Acrescentado a isso, as silabas que precedem uma soante palatal são sempre leves, como pode ser observado não só na completa ausência de rimas pesadas precedendo uma soante palatal intervocálica, como também no algoritmo de silabificação, que cria hiato no caso de seqüências de Vogal + Vogal Alta que precedem $/ \tilde{\mathrm{n}}, \Lambda /$ (moinbo, faúlba), enquanto antes de $/ \mathrm{m}, \mathrm{n}, \mathrm{r}, \mathrm{l} /$, os ditongos decrescentes surgem obrigatoriamente (queima, baila). Além disso, se uma soante palatal ocorre como onset de uma sílaba em final de palavra, como em alcunba, o acento da palavra nunca cai na antepenúltima sílaba, embora o acento proparoxítono seja um padrão possível no PB.

Neste texto, apresentarei uma explicação unificada para todos esses fatos, propondo que as soantes palatais são, de fato, geminadas fonológicas.

\section{A RESTRIÇÃO DE RIMA MÁXIMA DO PB}

Assumirei que a estrutura da silaba do PB é como em $(1,2)$, em que apenas a estrutura da rima é formalmente explícita, porque só essa parte da sílaba é relevante para nossa discussão, (veja também WETZELS, 1991). Em (1), V representa uma unidade de peso (ou mora) que domina um segmento [+vocálico], enquanto C na Rima representa uma unidade de peso (ou mora) que domina um segmento definido pelos traços [-vocálico, -aproximante, +soante] ou /s/. Linhas pontilhadas representam elementos opcionais. 
(1)

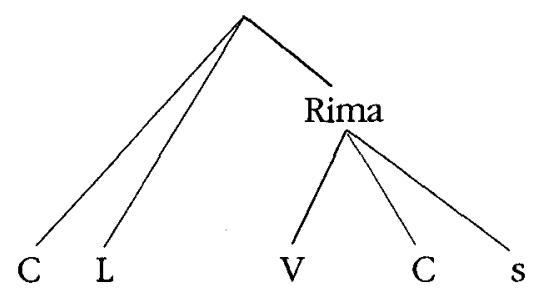

A restrição mais importante para o resto de nossa discussão é que a rima da sílaba do $\mathrm{PB}$ pode conter no máximo duas posições, apenas excepcionalmente três, e o terceiro elemento deve ser /s/. Chamarei isso de Restrição de Rima Máxima (RRM).

Já se observou que, abstraindo-se o comportamento excepcional de /s/, a sílaba do PB permite apenas duas posições na rima. Além disso, a posição de não-núcleo é exclusivamente reservada a segmentos soantes (vogais, líquidas e a mora nasal) ou /s/. A rima da sílaba do PB pode, portanto, ser representada formalmente como em (2):

(2) Rima da sílaba no PB

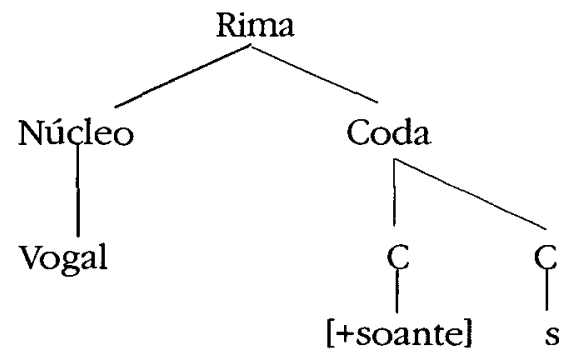

$\mathrm{O} P B$ tem sílabas abertas e travadas. As vogais nasais se comportam como rimas pesadas com relação àquelas regras do $\mathrm{PB}$ que são sensíveis ao peso da silaba. Para o $\mathrm{PB}$, podemos usar a noção de "rima pesada" em sua interpretação mais geral, que é aquela segundo a qual qualquer silaba que tenha duas posições preenchidas na rima conta como pesada. Uma lista exaustiva de rimas do PB é fornecida em (3): 
(3) Rimas pesadas no PB

Rimas possíveis

Ilustrações

$\begin{array}{lll} & \text { Final de palavra } & \text { Pré-final } \\ \mathrm{Vr} & \text { abajur } & \text { aberto } \\ \mathrm{V} 1 & \text { anel } & \text { asfalto } \\ \mathrm{Vs} & \text { cortês } & \text { adestro } \\ \text { Ditongos orais } & \text { herói } & \text { eleito } \\ \text { Ditongos nasais } & \text { irmão } & \text { cãibra } \\ \text { Vogais nasais } & \text { irmã } & \text { macumba }\end{array}$

Claramente, se a rima do $\mathrm{PB}$ contém maximamente duas posições, é previsto que as sílabas que contenham vogais nasais ou ditongos não possam ser seguidas por uma líquida tautossilábica, ou que silabas que terminem em uma líquida não possam ser seguidas por uma consoante nasal na mesma sílaba. Essa previsão é confirmada pelos fatos.

\section{A ASSIMETRIA NA REGRA DE NASALIZAÇÃO ALOFÔNICA}

Além das vogais nasais contrastivas, que são usualmente ${ }^{1}$ representadas na ortografia por uma consoante nasal na coda da sílaba (campo, pente, banco), o PB apresenta outro tipo de nasalização, que é desencadeada por uma consoante nasal intervocálica, em que o traço nasal se espraia para o(s) elemento(s) vocálico(s) da sílaba aberta imediatamente precedente (men[i]na, c[ã]ma, etc.). Enquanto a nasalização contrastiva é obrigatória em algum ponto na seqüência em que ocorre, como pode ser visto em palavras como $C[\tilde{a}] m p i n a s$ e $c[\tilde{a}] m p o$, em que o acento na sílaba pré-final em ambas as palavras e a nasalização antes da coda nasal $/ \mathrm{m} /$ é obrigatória, a nasalização alofônica é o resultado de uma regra variável, sensível tanto à variação lingüística quanto à não-lingüística (MORAES \& WETZELS, 1992; ABAURRE \& PAGOTTO, 1996). Para todos os dialetos do $\mathrm{PB}$, a nasalização alofônica é mais sistemática nas vogais 
acentuadas. Na verdade, muitos falantes do $\mathrm{PB}$ realizam uma alternância entre a raiz /am/ do verbo amar, como em formas do tipo ámo, com uma nasal /ã/, e amárem que /a/ é oral (VANDRESEN, 1975). Exemplos ${ }^{2}$ que mostram nasalização alofônica são fornecidos em (4).

(4) Nasalização alofônica

(4a) Acentuada antes de /n,m/

$\begin{array}{llll}\text { [si nu] } & \text { sino } & \text { [fumu] } & \text { fumo } \\ \text { [lemi] } & \text { leme } & \text { [dõnu] } & \text { dono }\end{array}$

(4b) Não-acentuada antes de $/ \mathrm{n}, \mathrm{m} /$

$\begin{array}{cccc}\text { [pinoja] } & \text { pinóia } & \text { [kumarí] } & \text { cumari } \\ \text { [tenás] } & \text { tenaz } & \text { [bonEka] } & \text { boneca } \\ & \text { [tamã.ku] } & \text { tamanco } & \end{array}$

(4c) Acentuada antes de / $\tilde{\mathbf{n}} /$

$\begin{array}{cccc}\text { [koziña] } & \text { cozinha } & \text { [awkuña] } & \text { alcunha } \\ \text { [azeña] } & \text { azenha } & \text { [segõña] } & \text { cegonha } \\ & \text { [arãña] } & \text { aranha } & \end{array}$

(4d) Não-acentuada antes de / $\tilde{\mathrm{n}} /$ [diñéjru] dinheiro [señóX] senhor

[kuñádu] cunhado
[veXgõñózu] vergonhoso [kãñótu] canhoto

Como pode ser observado nas palavras apresentadas em (4), a distinção entre a coronal e a plosiva nasal labial, por um lado, e a plosiva nasal palatal, por outro lado, é motivada por uma diferença na escolha de seus alvos para o espraiamento da nasalidade. Muito surpreendentemente, a nasalização é muito mais geral antes de $/ \tilde{\mathbf{n}} /$ do que antes de $/ \mathrm{n}, \mathrm{m} /$. Para ser mais preciso, a nasalização alofônica antes de nasais palatais ocorre independentemente da posição do acento primário, como a nasalização contrastiva. A força desse fenômeno foi confirmada por uma pesquisa desenvolvida recentemente no Brasil, cujos resultados são relatados em ABAURRE \& PAGOTTO 
(1996). Os pesquisadores observaram que a nasalidade contrastiva foi realizada em 100\% dos casos. Além disso, a nasalização alofônica foi categórica em sílabas de acento primário. Eles então observam: "A nasalização é categórica quando a vogal precede uma consoante nasal palatal, independentemente do contexto tônico ou átono" (ABAURRE \& PAGOTTO, 1996:24).

Caso se permita explicar o comportamento similar da nasalidade contrastiva e a nasalização alofônica antes de $/ \tilde{\mathrm{n}} /$, em termos de uma representação lexical similar, deve-se admitir a idéia de que nos casos do $/ \tilde{n} /$ a nasalidade é também localizada na coda, como em campo, etc. Uma forma de codificar essa hipótese fonologicamente é considerar as soantes palatais como geminadas lexicais / ñn, $K K /$. Certamente, a conseqüência imediata dessa proposta é que a ocorrência de uma soante palatal tornará a sillaba precedente pesada. Levando-se em conta a RRM, as soantes palatais nunca poderiam ser precedidas por uma sílaba pesada.

Consideremos, para verificar esse fato, as palavras em (5):

$\begin{array}{ll}\text { alma } & \text { vulnerável } \\ \text { arma } & \text { adorno } \\ \text { abismo } & \text { cisne } \\ \text { teimar } & \text { reino } \\ \text { fleuma } & \text { eunuco } \\ \text { andaime } & \text { paina } \\ \text { trauma } & \text { baunilha }\end{array}$

${ }^{*}$ VlñV
${ }^{*}$ Vrñ $V$
${ }^{*}$ VsñV
${ }^{*}$ eiñ $V$
${ }^{*}$ euñV
${ }^{*}$ aiñ $V$
${ }^{*}$ auñ $V$

Não é difícil ver que $/ \tilde{n} /$ se comporta diferentemente de $/ m, n /$. Os exemplos em (5) mostram que $/ \mathrm{m}, \mathrm{n} /$ podem ser precedidos por uma rima ramificada (ou sílaba pesada), mas que /ñ/ não pode. Devido à Restrição da Rima Máxima, e sob a hipótese de que as consoantes palatais são geminadas fonologicamente, predizemos que a última pode apenas se superficializar precedida por uma rima não-ramificada, isto é, uma só vogal. Isso porque a primeira parte da consoante palatal, que é, por hipótese, uma consoante dupla, já ocupa a segunda posição de rima da sílaba imediatamente prece- 
dente. Conseqüentemente, há, naquela sílaba, apenas uma posição disponível, que pode ser ocupada somente por uma vogal.

A hipótese da geminada não só explica por que as consoantes palatais nunca podem ser precedidas por uma rima pesada. Ela também implica que, se / $\tilde{n} /$ ocorre entre as duas últimas vogais de uma palavra que seja pelo menos trissilábica, o acento nunca poderá pular a sílaba pré-final. Isso porque no $\mathrm{PB}$ as palavras proparoxítonas com uma sílaba pesada pré-final (por exemplo, hipoteticamente, *rápindo, "ámeixa, * Géraldo, etc.) não existem. Mais uma vez, essa previsão é corroborada pelos fatos:

$$
\begin{aligned}
& \text { alcúnha } \\
& \text { camínho } \\
& \text { cozínha } \\
& \text { desénho } \\
& \text { façánha }
\end{aligned}
$$

Como previsto, palavras com a estrutura como as de (6) nunca poderiam ter acento na terceira sílaba da direita.

Além disso, / /̃/ não ocorre em início de palavras. Interessante observar que uma palavra como nboque, emprestada do italiano gnocchi, é pronunciada por alguns falantes como [iñoki], e por muitos outros como [(i $\rightarrow$ jjoki]. Obviamente, $/ \tilde{\mathrm{n}} /$ é considerado ser complexo em algum sentido, e sua complexidade é apenas tolerada em posição intervocálica. Provavelmente porque sua articulação complexa pode ser dividida sobre duas sílabas.

É obvio que a hipótese de que / $\tilde{\mathrm{n}} /$ se divide sobre duas sílabas teria força se fosse o caso de que a outra soante palatal do $\mathrm{PB}$, a palatal $/ \Lambda /(<\mathrm{lh}>)$, mostrasse um comportamento paralelo a $/ \tilde{\mathrm{n}} /$. Antes de $/ K /$, as rimas ramificadas de qualquer tipo, incluindo vogais nasais, são proibidas. Quando o $/ K /$ aparece entre as duas vogais finais de uma palavra que contenha mais de duas sílabas, o acento é invariavelmente na silaba pré-final. Finalmente, exceto para alguns clíticos como lhe, lhes, lha $(<l b e+a)$ e lho $(<l b e+o)$, que são dificilmente usados no $\mathrm{PB}$ coloquial, o $/ K / \mathrm{em}$ início de palavra é, 
muitas vezes, pronunciado com um /i/ protético, como em lhama, emprestado do espanhol llama, pronunciado como [i]lhama.

\section{A SILABIFICAÇÃO DAS VOGAIS ALTAS DIANTE DAS SOANTES PALATAIS}

Lembro que em (5) foi ilustrado que $/ \tilde{\mathrm{n}}, \Lambda /$ não podem ser precedidas por uma rima ramificada. Isto, certamente, não equivale a dizer que essas consoantes não podem ser precedidas por uma seqüência de vogais do tipo $/ \mathrm{V}\{\mathrm{i}, \mathrm{u}\} /$. No $\mathrm{PB}$, de fato, este é um padrão muito comum, como mostram as palavras em (7): ${ }^{3}$

$\begin{array}{ll}\text { rainha } & \text { bainha } \\ \text { ladainha } & \text { moinha } \\ \text { moinho } & \text { tainha } \\ \text { fuinha } & \text { fuinho } \\ \text { graúlho } & \text { faúlha }\end{array}$

Normalmente, seqüências de Vogal + Vogal Alta são obrigatoriamente silabificadas no PB para formar ditongos decrescentes, como pode ser visto em teimar, reino, fleuma, eunuco, andaime, paina, rauma, baunilba, etc. Por outro lado, as mesmas seqüências são analisadas como bissilábicas, se elas são seguidas por um grupo consonantal que não pode funcionar como onset de silaba complexa ou quando a seqüência de vogais é seguida por uma consoante no final da palavra. Considere, para ver isso, as palavras em (8), em que \$ marca uma fronteira silábica:

$\begin{array}{llll}\text { (8) pau\$lo } & \text { Paulo } & \text { pa\$úl } & \text { paul } \\ & & \text { ra\$úl } & \text { Raul } \\ & \text { se\$úl } & \text { Seoul } \\ \text { jai\$ro } & \text { Jairo } & \text { jaír } & \text { Jair } \\ & & \text { ada\$1 } & \text { adail } \\ & & \text { alda\$ír } & \text { Aldair } \\ & & \text { ada\$ír } & \text { Adair } \\ & & \text { valte\$ír } & \text { Valteir } \\ & & \text { ra\$1da } & \text { Railda }\end{array}$


A diferença na silabificação entre Paulo, com um ditongo decrescente, por um lado, e paul, com hiato, por outro, regularmente resulta da RRM. A seqüência /ul/ em paul é analisada como uma silaba independente, porque a acumulação de /aul/ em uma só silaba formaria uma rima triposicional de um tipo que é excluída pela RRM. De forma interessante, a estrutura geminada que é reivindicada para as soantes palatais prevê que a estrutura da sílaba sempre partirá a seqüência /Vi,u/ em duas sílabas antes de / $\tilde{\mathrm{n}} /$. Isso, na verdade, sempre acontece. Em minha opinião, as palavras em (7) são interessantes por duas razões. Primeiro, críticas ao apresentado aqui poderão especular que $o$ fato de $/ \tilde{\mathrm{n}} /$ nunca ser precedido por uma consoante fechando a sílaba precedente poderia ser atribuído a acidente histórico, e, sincronicamente, ser considerado como uma lacuna acidental. Contudo, como as palavras em (7) mostram, o mesmo não pode ser reivindicado com vistas ao fato de que /ñ / não pode ser precedido por um ditongo, uma estrutura que as regras de silabificação obrigatoriamente se constroem antes de $/ \mathrm{n} / \mathrm{ou} / \mathrm{m} /$ intervocálicos. Apenas sob a hipótese de que as palatais representam geminadas fonológicas pode-se explicar a falta sistemática de ditongos antes de $/ \tilde{\mathrm{n}} /$. Segundo, o fato de que soantes palatais nunca permitem que o acento caia na sílaba antepenúltima resulta do fato de que sua estrutura geminada torne a sillaba pré-final pesada. Conseqüentemente, a propriedade de stress-attracting de $/ \tilde{\mathrm{n}}, K /$ não tem nada a ver com a palatalidade desses sons, mas com sua natureza geminada.

\section{CONCLUSÃO}

Na discussão precedente, vimos que as soantes palatais são, em muitos aspectos, diferentes de todas as outras soantes. Elas são limitadas à posição intervocálica no conteúdo das palavras, desencadeiam obrigatoriamente a nasalização alofônica da vogal precedente, não permitem uma silaba pesada precedente, a vogal que imediatamente as precede é sempre acentuada, forçam uma seqüência Vogal + Vogal Alta precedente para silabificar como um hiato e tendem a 
ser "abrasileiradas", se ocorrem no início de palavras emprestadas de outras línguas. Mostramos que a hipótese de que esses sons representam geminadas fonológicas fornece uma explicação unificada para todos esses fatos.

\section{NOTAS}

* Meus agradecimentos a Dermeval da Hora por traduzir o texto original em inglês para português. Este texto representa uma versão revisada de parte de um estudo maior sobre a representação da nasalidade em português, publicado como WETZELS (1997).

${ }^{1}$ No caso específico de /a/, quando final da palavra ou parte de um ditongo nasal, o diacrítico ortográfico < > é usado para marcar nasalidade contrastiva: lã, mãe, etc. No interior de palavra [ãj] a prática ortográfica permite tanto <ãi> como $<$ aiM/n>, como visto em cãibra versus caimbra.

${ }^{2} \mathrm{~A}$ limitação da nasalização alofônica a sílabas acentuadas é atípica nos dialetos do Norte e Nordeste. Os fatos, como apresentados em (4), não se aplicam aos dialetos falados naquelas partes do Brasil.

${ }^{3}$ As convenções ortográficas do PB prescrevem o uso de um acento agudo sobre a vogal alta, se a última não combina com a vogal precedente em um ditongo: saúdo, país. Contudo, nenhuma marca de acento ortográfico é exigida, se a vogal alta que falta para formar um ditongo com a vogal precedente é seguida por uma nasal em final de palavra ou consoante líquida (paul, amendoim), por uma seqüência no interior da palavra de uma consoante soante + consoante (ainda, Railda 'id'), ou antes de $<\mathrm{nh}\rangle$ (rainha). Suficientemente estranha, essa prática que parece claramente inspirada na fonologia não se estende a $\langle\mathrm{lh}\rangle$ : deve-se escrever faullha com o acento agudo. 


\section{REFERÊNCIAS BIBLIOGRÁFICAS}

ABAURRE, M. Bernadete, PAGOTTO, Emílio G. Nasalização no Português do Brasil. In: KOCH, I. V. (Ed.). Gramática do português falado VI. Campinas: Editora da UNICAMP, 1996.

MORAES, J., WETZELS, W. Leo. Sobre a duração dos segmentos nasais e nasalizados em Português: um exercício de fonologia experimental. Cadernos de Estudos Lingüisticos, UNICAMP, 23, p.153-166, 1992.

VANDRESEN, Paulino. O vocalismo português: implicações teóricas. Revista Brasileira de Lingüistica, 2, p.80-103, 1975.

WETZELS, W. Leo. Mid vowel neutralization in Brazilian Portuguese. Cadernos de Estudos Lingüísticos, UNICAMP, 23, p.19-55, 1972.

. Mid vowel alternations in the Brazilian Portuguese verb. Pbonology, 12, p.281-304, 1995.

. The lexical representation of nasality in Brazilian Portuguese. Probus, 9, p.203-232, 1997 .

. The sound structure of Brazilian Portuguese. (em preparação). 